\title{
Without Funding Devolution will Fail
}

\author{
Kailash Chand MBBS FRCGP \\ Honorary Vice President of the British Medical Association (BMA), GP \& ex-chair of Tameside \\ and Glossop NHS \\ kchand@btconnect.com
}

Cite as: Chand, K. (2017) Without funding devolution will fail. Sushruta 10(1): 10 DOI: 10.38192/10.1.3

We are in uncertain times for the future of our NHS.

In a surprise deal on 2nd November 2014, George Osborne, a Conservative Secretary of State for Finance, and Sir Howard Bernstein, the then CEO of Labour controlled City of Manchester, signed an unprecedented derogation of power from Whitehall to Greater Manchester. Thus, Greater Manchester became the first English region to be handed full control of its $f 6 \mathrm{bn}$ health budget. Devolution Greater Manchester, or DevoManc as it is commonly dubbed, holds out the promise of meaningful and deep integration within the health service, and between health and social care.

This integration has great potential to offer real benefits to patients. In particular, it could help to deliver genuinely patient- centred and coordinated care on a locality basis. The existing barriers created since the origins of the NHS in 1947 between primary care, hospitals and social care are being redefined so that care can be seamless and less fragmented. The economic disparity between London and Manchester had created a health gap that could only be redressed by bringing the NHS under local control.

Of course the devolution of powers to Greater Manchester is not without risks. Aside from the reputational risk, the first requirement is to ensure that the public in general is on board and actually understand the scope and limitations of DevoManc, and then there is the more serious challenge of meaningful engagement to deliver its strategy and aspirations. Much of this was set up in the MOU that was signed in April 2015 with the aim that 'All decisions about Greater Manchester will be taken with Greater Manchester'. This is an experiment that we can't afford to botch-up otherwise it will emit toxic fumes for a long time to come.

While people want to have their voices heard, I am concerned that up until now our public, the voluntary sector and professionals have not been offered sufficient involvement in the devolution process. Some don't know what it is, whilst others see it as just another layer of bureaucracy - another political gimmick and less power for the people. These new deals have been done with no public awareness, no public consultation, no democratic engagement, no scrutiny and no impact assessment. 
The NHS in Greater Manchester is under intense pressure with more than 200,000 patients on the waiting list and hospital deficits hitting record highs. As hospital figures reveal, more than half of NHS Trusts are unable to balance their books and nearly three-quarters of NHS trusts have seen patients waiting more than 100 days for discharge in the past three years.. If there was ever any doubt of the evidence, it has lately become patently obvious that austerity has had an adverse impact on key aspects of patient care such as operations, cancellations of clinics, delayed discharges, etc. It is clear now, more than ever, that chronic underfunding is preventing NHS staff from providing patients with the level of care they deserve.

Devolution presents a real opportunity for Greater Manchester to deal with some of the problems facing the NHS, and also some of the more longer-term public health challenges, especially around health inequalities in a diverse population where health outcomes are significantly worse than the rest of the country in many areas such as respiratory disease, stroke-related illness, cancer, psychiatric disorders, etc. But without the right financial support, it is going to be an uphill task running our clinical services, let alone meeting with the health and social challenges. Social care in particular is in an abyss - in Greater Manchester for 2016/17, we are facing an $\mathrm{f} 81 \mathrm{~m}$ black hole in social care funding, rising to almost a quarter of a billion pounds by 2020 - yet this Government feels grammar schools are a greater funding priority than care for older people.

One of the real issues for this devolution is to ensure that all services remain stable and are invested in and that we don't have a situation of robbing Peter to pay Paul. The threats and the opportunities are significant. If the DevoManc team do not use the $f 6 b n$ devolved budget in a radically different way around our health and social care system, it will face a major deficit of $£ 2$ bn by 2021 - a recipe for another NHS reorganisation failure. The NHS has already been seriously damaged by the policies of all three major political parties in the last decade. If this continues, England will have a completely different healthcare system in five years' time 'NHS' in name alone. Things will be much worse in terms of access, equity, health outcomes and cost. However, Manchester devolution can be an inspiration for the rest of the country when it comes to creating the NHS of the future

\section{Conclusion}

I feel passionately that with Andy Burnham, the new mayor of Greater Manchester, and Jon Rouse, chief officer of health and social care partnership, fighting our corner, championing Greater Manchester nationally and internationally our prospects are much brighter than if it were to be left to Theresa May in Westminster. Manchester as Andy says, is the home of radical forward thinking and we have a real job of work to do to change a 20th Century treatment service into a 21st Century health promotion service. We have the ability to be the pioneers of that paradigm shift." With a Mayor with real power, real clout and real influence, we are in a stronger position to ensure that the interests of our great region of Greater Manchester are not just protected as we leave the EU, but that we flourish, thrive and achieve our amazing potential. Make the NHS and social care, safe and best.

https://www.kingsfund.org.uk/blog/2015/03/devo-manc-health-social-care-wellbeinggreater-manchester 